\title{
Correction to: A study on the role of articular cartilage soft tissue constitutive form in models of whole knee biomechanics
}

\author{
Benjamin C. Marchi ${ }^{1}$. Ellen M. Arruda ${ }^{1}$
}

Published online: 22 November 2018

(c) Springer-Verlag GmbH Germany, part of Springer Nature 2018

\section{Correction to:}

\section{Biomech Model Mechanobiol}

https://doi.org/10.1007/s10237-016-0805-2

lateral collateral ligament (LCL) and medial collateral ligament (MCL) were switched in the original Fig. 1a. The

Based on a reader comment, it has become clear that, in the originally published version of the article, Fig. 1 was published with incorrect anatomical labels. In particular, the

The original article can be found online at https://doi.org/10.1007/ s10237-016-0805-2.

\footnotetext{
Benjamin C. Marchi

bmarchi@umich.edu

Ellen M. Arruda

arruda@umich.edu

1 University of Michigan, 2350 Hayward St., Ann Arbor, MI 48109, USA
} 


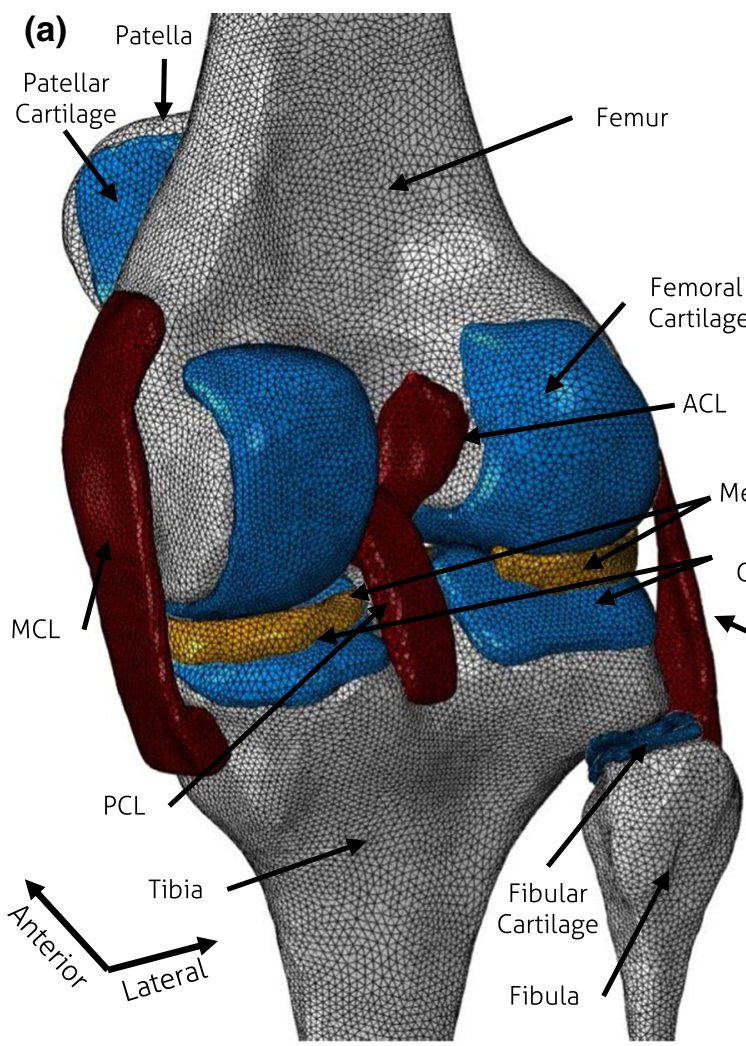

(c)

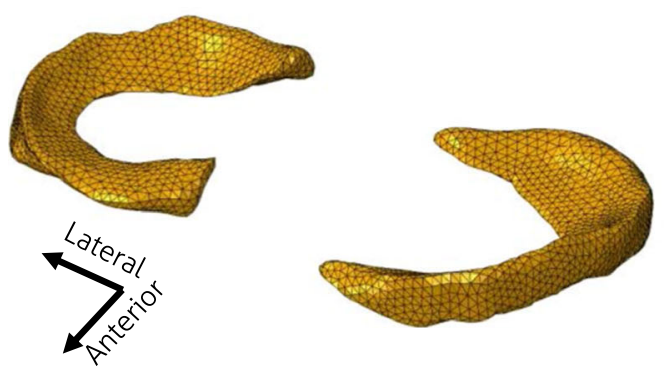

Fig. 1 (a) Computational FE model of the right knee of a healthy adult female and its soft tissue constituents. The geometric accuracies of the articular cartilage (b), menisci (c), and supporting ligaments (d) are

(b)

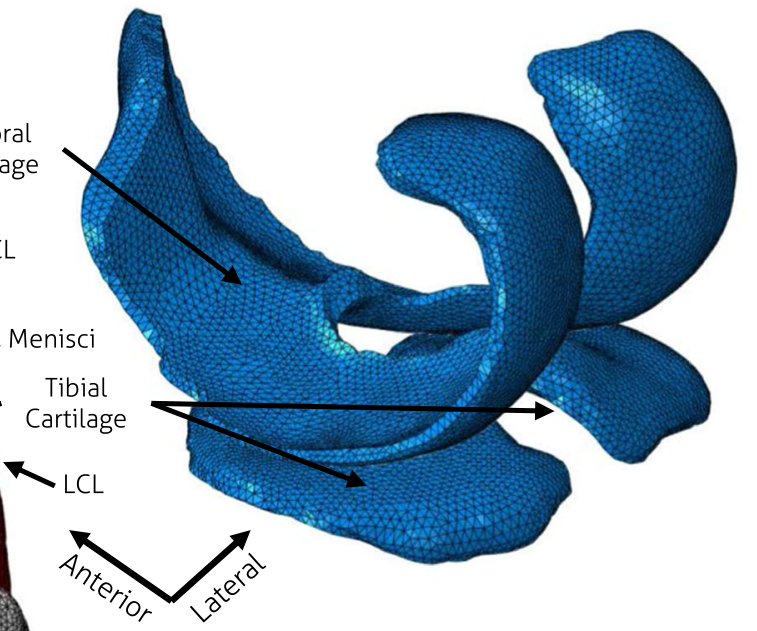

(d)

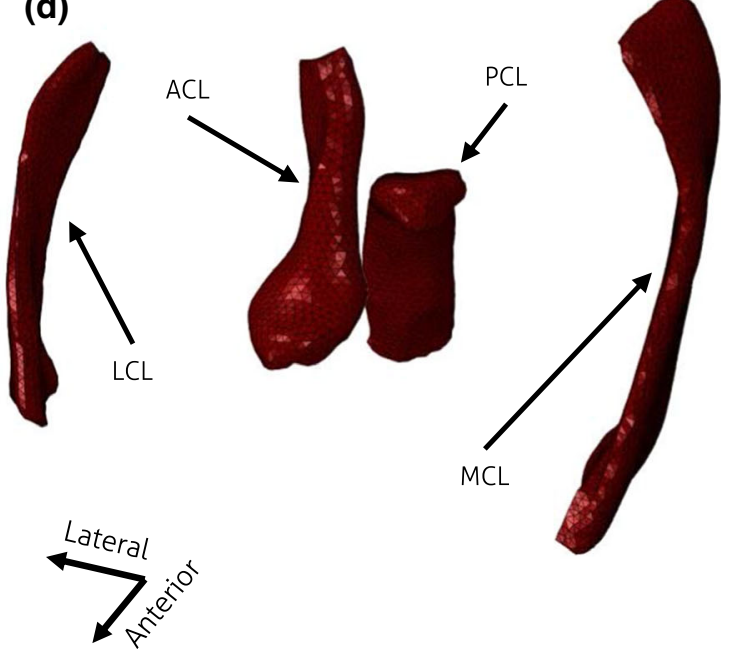

highlighted. In each figure, cartilage is displayed in blue, menisci in orange, ligaments in red, and bones in white

Publisher's Note Springer Nature remains neutral with regard to jurisdictional claims in published maps and institutional affiliations. 